\title{
Molecular biology of toll-like receptors
}

\author{
Zoltan Szatmary \\ Slovak Medical University, Limbová 12, 83303 Bratislava, Slovak Republic
}

\begin{abstract}
Toll-like receptors (TLRs) play important roles in host resistance to infections, but also act as mediators of pathologies in autoimmunity, septic shock, metabolic disease and cancer. TLRs are expressed in sentinel cells of the immune system (most notably dendritic cells and macrophages) and are key sensors of bacteria, viruses, fungi and protozoa (O'Neill 2006). TLRs also recognize endogenous ligands present in tissues and cells in the absence of infection (Kawai and Akira 2005; Nizet 2006; Kim et al. 2009). In this review, the TLRs are characterized at the cellular level with emphasis on TLR-mediated signaling pathways along with their negative regulation, including specificity of the response(s) at the promoter level.
\end{abstract}

Key words: Toll-like receptor - Adaptor - Signal transduction - Inflammation - Anti-viral response

\begin{abstract}
Abbreviations: Btk, Bruton's tyrosine kinase; IFN, interferon; IKK, inhibitor $\mathrm{kB}$ kinase; IL-1R, interleukin-1 receptor; IP, IFN-inducible protein; IRAK, IL-1R-associated kinase; IRF, IFN regulatory factor; JNK, c-Jun N-terminal kinase; LPS, lipopolysaccharide; Mal, MyD88 adapter-like; MAPK, mitogen-activated protein kinase; MCP, monocyte chemotactic protein; MyD88, myeloid

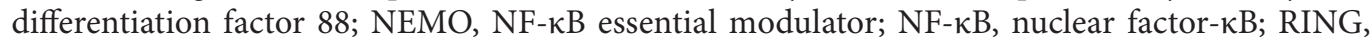
really interesting new gene; RIP, receptor-interacting protein; SOCS, suppressor of cytokine signaling; TAB, TAK1-binding protein; TAK1, transforming growth factor (TGF)- $\beta$-activated kinase 1 ; TBK1, TRAF family member-associated NF-kB activator (TANK)-binding kinase 1; TIR, Toll/IL-1R; TLR, toll-like receptor; TNF, tumor necrosis factor; TRAF, TNF receptor (TNFR)-associated factor; TRAM, TRIF-related adaptor molecule; TRIF, TIR domain-containing adaptor-inducing IFN- $\beta$; Ubc, ubiquitin-conjugating enzyme; Uev1A, ubiquitin E2 variant 1A.
\end{abstract}

\section{Introduction}

Toll-like receptors (TLRs) are type I transmembrane proteins, whose name was coined based on similarity to Toll, a developmental control gene identified in the fruit fly Drosophila melanogaster in 1985 (Hansson and Edfeldt 2005). In 1996, it was found that Toll also activates the synthesis of anti-microbial peptides, thus protecting the fly from infections (Lemaitre et al. 1996). TLR4 was the first mammalian TLR to be identified by its role in lipopolysaccharide (LPS)-responsiveness and based on its homology to Toll. Currently, the TLR family has 11 members (Ulevitch 1999; Underhill et al. 1999).

Correspondence to: Zoltan Szatmary, Slovak Medical University, Limbová 12, 83303 Bratislava, Slovak Republic

E-mail: zoltan.szatmary@szu.sk
Whereas TLR1, TLR2, TLR4 and TLR6 mainly recognize bacterial and fungal cell wall components, such as LPS and lipopeptides and TLR5 binds flagellin (a monomeric constituent of bacterial flagella) (Hayashi et al. 2001), TLR3, TLR7, TLR8 and TLR9 recognize nucleic acid structures, which serve as molecular signatures for viral infections (Dunne and O'Neill 2005). Consistent with their role in microbial recognition, TLR1, 2, 4, 5 and 6 are expressed on the surface of myeloid lineage cells, whereas TLR3, 7, 8 and 9 are localized in endosomal/lysosomal membranes, a location that is more suitable for recognition of viruses (Gewirtz et al. 2001; Dunne and O’Neill 2005).

The cytoplasmic regions of TLRs share a protein motif known as the Toll/interleukin-1 receptor (IL-1R) (TIR) domain, which mediates homotypic associations between TLRs and TIR-containing adaptors (Hayashi et al. 2001). The structure of the TIR domain consists of a central five- 
stranded parallel $\beta$-sheet $(\beta A-\beta E)$ surrounded by five helices $(\alpha \mathrm{A}-\alpha \mathrm{E})$ (Watters et al. 2007). Upon ligand-induced TLR dimerization or oligomerization, it is thought that a conformational change occurs in the cytoplasmic TIR domains that allows the recruitment of cytoplasmic adaptor proteins and subsequent engagement of downstream signaling molecules. Several proteins that interact with the TIR domains of TLRs were identified, including myeloid differentiation factor 88 (MyD88), MyD88 adapter-like (Mal)/TIR domain-containing adapter protein (TIRAP), TIR domain-containing adaptor-inducing interferon (IFN)- $\beta$ (TRIF) and TRIF-related adaptor molecule (TRAM) (Table 1).

The first cytoplasmic adaptor found to be recruited to ligand-activated TLRs is myeloid differentiation factor 88 (MyD88), originally identified as a myeloid primary response gene rapidly induced by IL- 6 in M1 myeloleukemic cells (Kawai and Akira 2005). MyD88 has a C-terminal TIR domain, which interacts with the TIR domain of all TLRs other than TLR3, while its $\mathrm{N}$-terminus harbors a death domain (DD), initially implicated in TLR-induced cell death (Aliprantis et al. 1999). TLR-induced apoptosis may play a role in resolution of inflammation by limiting the number of activated cells that produce pro-inflammatory mediators (Aliprantis et al. 1999), but can also compromise innate im-

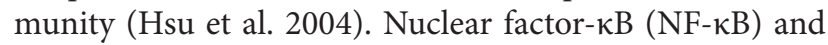
mitogen-activated protein kinases (MAPKs) are still weakly activated in the absence of MyD88, but tumor necrosis factor (TNF) is not produced in the absence of MyD88 (Gohda et al. 2004; O'Neill 2006).

MyD88 adapter-like (Mal) (Fitzgerald et al. 2001), also known as TIR domain-containing adapter protein (TIRAP) (Horng et al. 2001), is a bridging adaptor for MyD88, recruiting it to the TIR domains of TLR2 and TLR4. Mal contains a C-terminal phosphatidylinositol 4,5-bisphosphate (PIP2)-binding domain, which serves to localize it and its partners (i.e. MyD88) to membranes. Phosphorylation of Mal by Bruton's tyrosine kinase (Btk) is required for efficient signaling (Watters et al. 2007).

TIR domain-containing adaptor-inducing IFN- $\beta$ (TRIF) is an adaptor protein for TLR3 and TLR4. In addition to the TIR domain it has a TNF receptor (TNFR)-associated factor (TRAF)6-binding motif in its $\mathrm{N}$-terminus, and a receptor-interacting protein (RIP) homotypic interaction motif (RHIM) in the C-terminus (Miggin and O'Neill 2006). Overexpression of TRIF preferentially activates the IFN- $\beta$ promoter (Akira 2003). In macrophages of Mal/MyD88 double knockout mice, genes encoding IFN-inducible protein (IP)-10, immune-responsive gene (IRG)-1 and glucocorticoid-attenuated response gene (GARG)-16 (which are IFN-related genes) were induced normally in response to LPS, suggesting the existence of a MyD88-independent pathway. This pathway is dependent on TRIF (Miggin and O’Neill 2006) and TRAM (see further).
TRIF-related adaptor molecule (TRAM) acts as a bridge to couple TRIF to TLR4 and is required for TLR4-mediated MyD88-independent responses (Dunne and O'Neill 2005; Arancibia et al. 2007). TRAM-deficient mice show defects in cytokine production and IFN- $\beta$ induction only in response to TLR4 (Gohda et al. 2004). TRAM is targeted to the cell membrane by $\mathrm{N}$-terminal myristoylation (Watters et al. 2007), which is essential for recruitment of TRIF to the membrane. Phosphorylation of TRAM on serine-16 by protein kinase $\mathrm{C}(\mathrm{PKC}) \varepsilon$ is necessary for signaling and correlates with its removal from the membrane (Watters et al. 2007).

The IL-1R-associated kinase (IRAK) family members IRAK1, IRAK2, IRAKM and IRAK4 contain an N-terminal death domain, a serine/threonine kinase domain and a TRAF-binding motif, which is absent from IRAK4 (Arancibia et al. 2007). IRAK1 and IRAK2 are essential for MAPK activation, but not for induction of NF- $\kappa B$ (Kawagoe et al. 2008). The most profound phenotype of IRAK1-deficient mice is a complete impairment of IFNa production (Uematsu et al. 2005); however, the exact role of IRAK1 in IFN induction is not clear. IRAK1 also has "PEST" sequences involved in proteolysis (Janssens and Beyaert 2003), and is ubiquitinated and degraded by the proteasome after TLR or IL-1R stimulation (Yamin and Miller 1997; Li et al. 1999). In contrast, the amount of IRAK2 is not altered in response to TLR stimulation (Kawagoe et al. 2008).

In response to TLR stimulation, IRAK4 phosphorylates IRAK1 (Kollewe et al. 2004). Phosphorylation of IRAK2 is also missing in IRAK4 ${ }^{-1-}$ macrophages (Kawagoe et al. 2007), suggesting that IRAK2 is also phosphorylated by IRAK4. These results indicate that IRAK4 acts upstream of both IRAK1 and IRAK2.

TNF receptor-associated factors (TRAFs) are really interesting new gene (RING) finger-containing proteins (with the exception of TRAF1) that share a conserved C-terminal "TRAF domain". Initially, TRAF6 was thought to be the sole member of this family to be involved in TLR signaling (Miggin and O'Neill 2006). All MyD88- and TLR-dependent triggered pathways, which lead to activation of NF- $\mathrm{KB}$ and MAPKs, require TRAF6 (Gohda et al. 2004). TRAF3 was only recently identified as a component of TLR signaling, being essential for the IFN response but not required for inflammatory cytokines and chemokines (Hacker et al. 2006; Miggin and O'Neill 2006). TRAF1, by contrast, may be involved in inhibition of some (anti-viral) TLR activities (Miggin and O’Neill 2006).

TRAF6 is a lysine 63 (K63)-specific E3 ubiquitin-protein ligase that functions together with ubiquitin-conjugating (Ubc) enzyme Ubc13 and ubiquitin E2 variant 1A (Uev1A) to catalyze the synthesis of K63-linked polyubiquitin chains on target proteins including TRAF6 itself (Kawagoe et al. 
2008). Ubc13 in collaboration with its cofactor Uev1A binds the RING finger domains of TRAF proteins to promote activation of protein kinases involved in signaling by TNFRs and TLRs (Deng et al. 2000; Wang et al. 2001). Unlike K48-linked polyubiquitination, which signals for proteasome-dependent protein degradation, K63-linked polyubiquitination is nondestructive and activates protein kinases (Fukushima et al. 2007). Knockout studies indicate that Ubc13, the only E2 dedicated to K63-linked ubiquitin conjugation is essential for TLR-dependent MAPK activation (Yamamoto et al. 2006).

In general, the ubiquitination pathway causes covalent attachment of one or more ubiquitin molecules to proteins through the sequential action of three enzymes. First, the ubiquitin-activating enzyme (E1) activates ubiquitin by forming a thioester bond between ubiquitin and cysteine at the active site of E1. Next, the activated ubiquitin is transferred to a ubiquitin-conjugating enzyme (E2, or Ubc) to form a thioester linkage. Finally, ubiquitin ligases (E3) recruit the E2s to specific targets and promote the formation of an isopeptide bond between ubiquitin and lysine residues on the target protein (Ciechanover 2006). There is only one E1, but many E2s, and even more E3s (Ciechanover 2006).

\section{Signaling elicited by activated TLRs}

After binding of MyD88 to ligand-activated TLRs, MyD88 recruits members of the IRAK family; particularly IRAK1 and IRAK4, through homotypic interactions between their death domains. IRAK4 then phosphorylates IRAK1 (and possibly IRAK2), which subsequently associates with TRAF6 (Miggin and O'Neill 2006). TRAF6 is then activated through self-ubiquitination with the assistance of Ubc13 and Uev1A (Watters et al. 2007; Kawagoe et al. 2008). TRAF6 and IRAK1 then dissociate from the receptor and interact with a membrane-bound pre-associated complex of transforming growth factor (TGF)- $\beta$-activated kinase (TAK) 1 - a member of the MAP3K family, and its binding proteins $\mathrm{TAB} 1$ and $\mathrm{TAB} 2$. The exact order of these events has not been determined; however, ubiquitination of TRAF6 is required for its interaction with TAB2, which binds to K63-linked polyubiquitin chains through its zinc finger domain (Evans 2005). Subsequently, phosphorylation of TAK1 and TAB2 induce IRAK1 degradation, leading to dissociation of the TRAF6:TAK1:TAB1:TAB2 complex from the membrane to the cytosol. TRAF6 then activates TAK1 and modifies NF- $\kappa$ B essential modulator (NEMO)/ inhibitor $\kappa \mathrm{B}$ kinase $(\mathrm{IKK}) \gamma$ - the regulatory subunit of the IKK complex, via K63-linked ubiquitination (Evans 2005; Arancibia et al. 2007). K63-specific ubiquitination of RIP1 maybe also important, causing RIP1 to bind TAB proteins (Evans 2005). Once activated, TAK1 phosphorylates IKK $\beta$. IKK activation during IL-1R/TLR signaling is thought to occur in the cytosol, which differs from IKK $\beta$ activation during TNFR1 signaling, where TRAF2 and IKK are recruited to the receptor complex through binding to RIP (Evans 2005). The activated IKK complex induces phosphorylation and subsequent degradation of $I \kappa B$, thereby leading to nuclear translocation of NF- $\mathrm{BB}$ and expression of pro-inflammatory cytokines. TAK1 also phosphorylates MAPK kinase (MKK)3, 4, 6 and 7, which in turn activate p38 and c-Jun N-terminal kinase (JNK) (Wang et al. 2001). The exact order of these events is poorly understood and the results described above only provide a rough outline of the mechanisms involved in IKK and MAPK activation.

It was also shown that TRIF bound to TLR3 recruits TRAF6 directly through a TRAF6-binding motif in its Nterminus (Doyle and O'Neill 2006). TRIF also associates with RIP1 through its C-terminal RHIM domain; and in the absence of RIP1, TLR3-mediated NF- $\kappa$ B activation is abolished, suggesting that RIP1 and TRAF6 mediate TRIFinduced NF- $\kappa$ B activation (Meylan et al. 2004). TRIF can also activate NF- $\kappa B$ through an alternative pathway. Pretreatment of MyD88-deficient cells with soluble TNFR1, or depletion of IFN regulatory factor (IRF)-3, blocked LPS-stimulated activation of NF- $\kappa \mathrm{B}$ indicating the involvement of TNF and IRF-3 (Doyle and O'Neill 2006). This might also explain why LPS-stimulated TRAF6-deficient macrophages are still capable of delayed NF- $\kappa \mathrm{B}$ activation

Table 1. Adaptor involvement in TLR signaling pathways

\begin{tabular}{|c|c|c|c|c|c|c|c|c|}
\hline Receptor & TLR1/TLR2 & TLR2/TLR6 & TLR3 & TLR4 & TLR5 & TLR7 & TLR8 & TLR9 \\
\hline Ligand & triacyl lipopeptides & diacyl lipopeptides & dsRNA & LPS & flagellin & ssRNA & ssRNA & $\mathrm{C}^{\star} \mathrm{pG}$ DNA \\
\hline MyD88 & + & + & - & + & + & + & + & + \\
\hline Mal/TIRAP & + & + & - & + & - & - & - & - \\
\hline TRIF & - & - & + & + & - & - & - & - \\
\hline TRAM & - & - & - & + & - & - & - & - \\
\hline
\end{tabular}

DNA, deoxyribonucleic acid; dsRNA, double-stranded ribonucleic acid; LPS, lipopolysaccharide; Mal, MyD88 adaper-like; MyD88, myeloid differentiation factor 88; ssRNA, single-stranded ribonucleic acid; TIRAP, toll/interleukin-1 receptor (IL-1R) (TIR) domain-containing adapter protein; TLR, toll-like receptor; TRAM, TRIF-related adaptor molecule; TRIF, TIR domain-containing adaptor-inducing interferon (IFN)- $\beta$. Adapted from O’Neill (2002). ${ }^{*} \mathrm{C}$ is unmethylated 
(through IRF-3-dependent de novo synthesis of TNF-a) (Miggin and O'Neill 2006).

LPS does not activate NF- $\kappa \mathrm{B}$ in RIP1/MyD88 double deficient cells indicating the requirement of RIP1 for TRIF-dependent TLR4-induced NF- $\kappa B$ pathway (CussonHermance et al. 2005). While MyD88 and Mal mediate the early phase of NF- $\kappa B$ activation, TRIF and TRAM mediate the late phase of NF- $\kappa \mathrm{B}$ activation and the second pathway that depends on production of IFN- $\beta$ ( $v i a$ the transcription factor IRF-3) (Dunne and O'Neill 2005; Sasai et al. 2005).

The N-terminus of TRIF also contains binding sites for the non-canonical IKK family members, IKKi/IKKe and TRAF family member-associated NF- $\kappa$ B activator (TANK)-binding kinase 1 (TBK1), which were discovered based on sequence homology and the potential to stimulate NF- $\kappa B$ signaling. It was believed that they associate with TANK (Dunne and O'Neill 2005), however, it was revealed that it is the TANK homolog, NAP1 (NF- $\kappa \mathrm{B}$-activating kinase (NAK)associated protein 1) that forms a functional complex with TBK1 and IKKi rather than TANK itself (Sasai et al. 2005). As mentioned, TRAF6 and RIP-1 are thought to mediate TRIF-induced NF- $\kappa$ B activation; whereas IKKi and TBK1 (with NAP1) are required for TRIF-induced IRF-3 activation (Dunne and O'Neill 2005), which also depends on TRAF3 (Hacker et al. 2006). The primary targets of the IKK-related kinases are IRF-3 and IRF-7, transcriptional mediators of anti-viral activities (Hiscott 2007).

Detection of virus infection and induction of appropriate anti-viral responses by producing type I IFNs (IFN- $\alpha$ and IFN- $\beta$ ) and IFN-related proteins, such as IP-10, a member of the CXC chemokine family, monocyte chemotactic protein (MCP)-1, GARG-16, IRG-1 and regulated and normal T cell expressed and secreted (RANTES)/CC chemokine ligand (CCL)5 (Gohda et al. 2004; Miggin and O'Neill 2006), is an important effector function of some TLRs. TRIF and/or TRAM activate the signaling pathway leading to production of IFN through activation of transcription factor IRF-3 in a manner dependent on the IKK-related kinases IKKi and TBK1 (Dunne and O'Neill 2005). The model of IRF-3 activation proposes that phosphorylation induces a conformational change that allows IRF-3 homo- or heterodimerization, nuclear localization and association with the coactivator CBP/p300. Phosphorylation-dependent association with $\mathrm{CBP} / \mathrm{p} 300$ retains IRF-3 in the nucleus and induces transcription of IFN- $\beta$, as well as other IFN-response genes. Recently, IRF-1 has been identified as an additional transcription factor activated by MyD88, inducing IFN- $\beta$, inducible NO synthase and IL-12p35 (Negishi et al. 2006).

IFN- $\alpha$ production requires the transcription factor IRF-7, which has been shown to associate with MyD88, IRAK1, IRAK4 and TRAF6 (Kawai et al. 2004; O'Neill 2006; Wat- ters et al. 2007). Ubc13 is also required for the activation of IRF-7 (Uematsu et al. 2005), but the K63-specific E3 ligase that is involved or its target are unknown (it could be TRAF3, see later). TBK1 and IKKi have been shown to phosphorylate and activate IRF-7 as well (Fitzgerald et al. 2003). IRF-5, like IRF-7, complexes with both MyD88 and TRAF6 (Takaoka et al. 2005). In IRF-5-deficient cells the induction of inflammatory cytokines is severely impaired, whereas IFN-a production is not affected (Watters et al. 2007).

Importantly, viral infection is also detected through TLR-independent mechanisms (Hiscott 2007). Early viral replicative intermediates are detected by two recently characterized cytosolic viral RNA receptors - RIG-I (retinoic acid-inducible gene-I) (Yoneyama et al. 2004) and Mda5 (melanoma differentiation-associated gene 5) (Andrejeva et al. 2004). Signaling by RIG-I and Mda5 to IRF-3 is also TRAF3-dependent (Pietras et al. 2006).

Evidences are beginning to emerge about the unique role of TRAF3 in TLR signaling. TRAF3 has been shown earlier to be essential for the induction of type I interferons and the anti-inflammatory cytokine IL-10 (Hacker et al. 2006), which in the case of TLR3 and TLR4 are dependent on IRF3 activation (Doyle et al. 2002). The IFN response can repress tumor growth and (especially IFN- $\beta$ ) has protective function in osteoporosis, whereas TNF and other inflammatory cytokines can promote tumor growth and bone resorption (Takayanagi et al. 2002, 2005; Luo et al. 2004; Lin and Karin 2007). New data indicate that the final outcome of TLR signaling - the selective production of type I IFNs versus proinflammatory cytokines, is controlled by differential ubiquitination of TRAF3 (Tseng et al. 2010). Whereas the TRIF-dependent response is critical for IFN and IFN-related gene induction, the induction of proinflammatory cytokines is mediated mainly by MyD88-dependent signaling (Yamamoto et al. 2002; Hoebe et al. 2003). TRIF-mediated signaling triggered K63-linked self-ubiquitination of TRAF3, and was shown to be essential for activation of IRF3 and the IFN response. By contrast, MyD88-dependent signaling led to degradative ubiquitination of TRAF3, resulting in induction of the inflammatory response through activation of MAPK. Activation of the K48-specific ubiquitin ligases cIAP1/2 (present only within the MyD88-assembled, but not within the TRIF-assembled signaling complex, which is sorted into endosomes) by its relative TRAF6 was required for ubiquitination of TRAF3.

In TLR signaling, the K63-specific polyubiquitination is mediated mainly by the ubiquitin-conjugating enzyme Ubc13. Whereas both TRAF2 and TRAF6 are K63-specific E3 ubiquitin ligases which require Ubc13, TRAF3 ubiquitination is not totally dependent on $\mathrm{Ubc13}$ (M. Karin, personal communication). Interestingly, it has been demonstrated that Ubc13 deficiency preferentially affects activation of MAP 


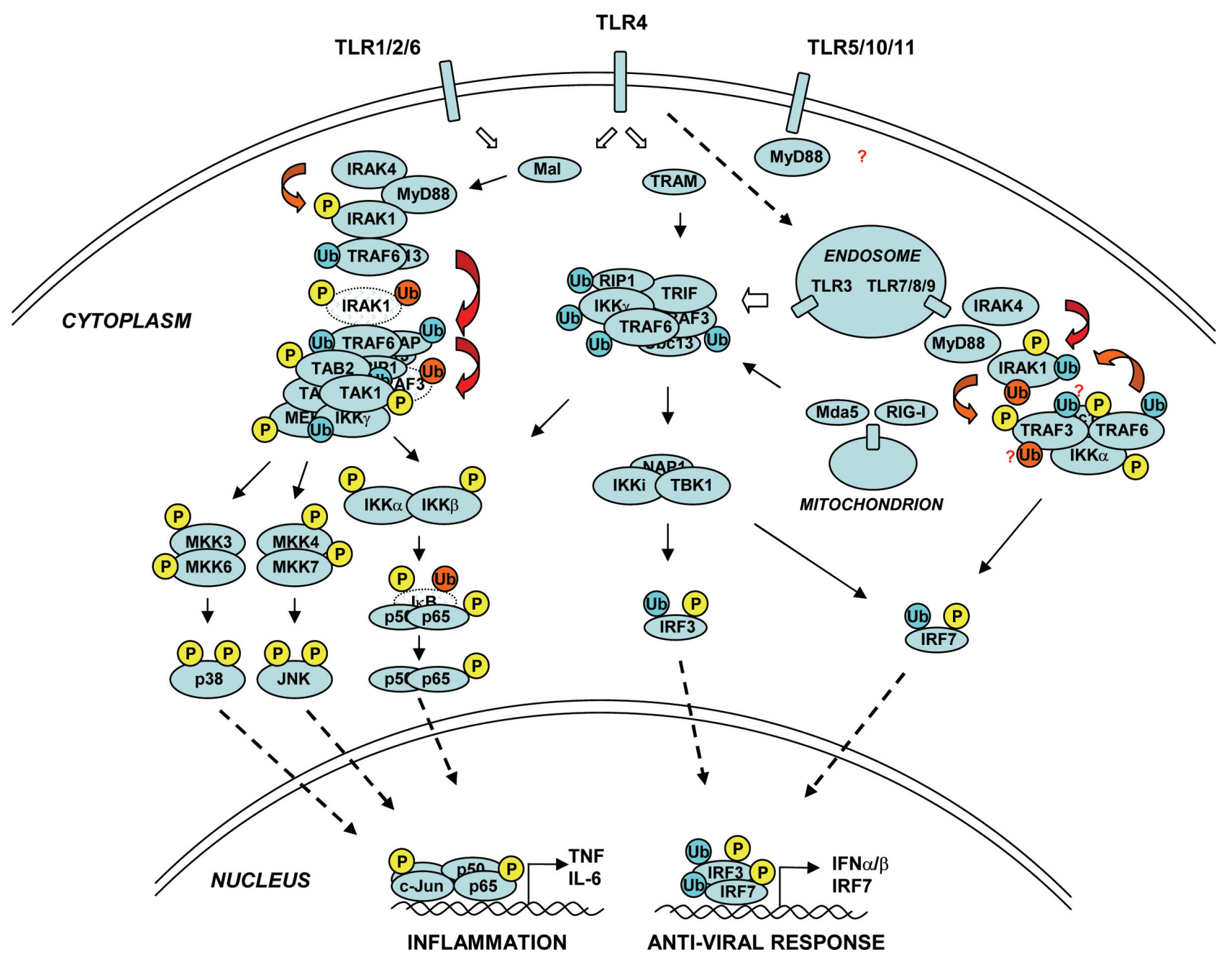

Figure 1. A simplified diagram of signal transduction pathways elicited by activated TLRs. IRFs can form homo- as well as heterodimers (only heterodimers are shown for the sake of simplicity). Circled P indicates phosphorylation, circled Ub denotes ubiquitination (red, degradative K48-linked; blue, K63-linked polyubiquitination). cIAP, cellular inhibitor of apoptosis; IFN, interferon; IkB, inhibitor кB; IKK, IкB kinase; IL, interleukin; IRAK, IL-1 receptor (IL-1R)-associated kinase; IRF, IFN regulatory factor; JNK, c-Jun N-terminal kinase; Mal, MyD88 adapter-like; Mda5, melanoma differentiation-associated gene 5; MEKK, mitogen-activated protein kinase (MAPK)/extracellular signal-regulated kinase (ERK) kinase kinase; MKK, MAPK kinase; MyD88, myeloid differentiation factor 88; NAP1, NF- $\kappa B$-activating kinase (NAK)-associated protein 1; RIG-I, retinoic acid-inducible gene-I; RIP1, receptor-interacting protein 1; TAB, TAK1-binding protein; TAK1, transforming growth factor (TGF)- $\beta$-activated kinase 1 ; TBK1, TRAF family member-associated NF- $\kappa$ B activator (TANK)-binding kinase 1; TLR, toll-like receptor; TRAF, tumor necrosis factor (TNF) receptor (TNFR)-associated factor; TRAM, TRIF-related adaptor molecule; TRIF, toll/interleukin-1 receptor (TIR) domain-containing adaptor-inducing IFN- $\beta$; Ubc13, ubiquitin-conjugating enzyme 13.

kinases and production of pro-inflammatory cytokines, providing additional level of specificity (Yamamoto et al. 2006).

It has been published recently that activation of signaling cascades at CD40 is a two-stage process, and only occurs upon release of the receptor-tethered signaling complex; mediated by the cellular inhibitor of apoptosis (c-IAP)dependent degradation of TRAF3, both components of the same signaling complex (Matsuzawa et al. 2008). Simi- larly, c-IAP-mediated degradation of TRAF3 is required in MyD88-dependent TLR signaling to MAPKs, and proceeds via the same two stage mechanism shown for CD40 (Tseng et al. 2010). TRAF6 activation, in addition to K63-linked self-ubiquitination, induces the Ubc13-dependent K63linked ubiquitination of c-IAP $1 / 2$; resulting in $\mathrm{c}$-IAP $1 / 2$ activation (as TRAF3 K48-specific E3 ligases), and degradation of TRAF3 (c-IAP is an anti-apoptotic protein with a K48-specific E3 ubiquitin-protein ligase activity, 
whose expression is induced by NF- $\mathrm{kB}$ ). Once TRAF3 is degraded, the entire MyD88-associated signaling complex translocates to the cytosol, where TAK1 is activated to allow MAPK signaling.

\section{Negative regulation of TLR signaling}

Inhibitory soluble forms of TLR2 and TLR4 have been described, produced by post-translational modification or alternative splicing, respectively (Arancibia et al. 2007).

A splice variant of MyD88, termed MyD88s, inhibits NF$\kappa \mathrm{B}$ by preventing the association IRAK1 with IRAK4, and the subsequent activation of IRAK1.

IRAKM, a kinase inactive IRAK family member, prevents the dissociation of IRAK1 from MyD88, and the subsequent association of IRAK1 with the downstream adaptor TRAF6 (Kobayashi et al. 2002).

Another TRAF family member, TRAF1, has been shown to interact with the TIR domain of TRIF, resulting in its inhibition (Miggin and O'Neill 2006).

Sterile $\alpha$ - and armadillo-motif containing protein (SARM), the fifth TIR domain-containing adaptor associates with TRIF and blocks TRIF-induced NF- $\mathrm{KB}$ activation (Carty et al. 2006; Watters et al. 2007). The mechanisms of SARM action involved its two tandem sterile $\alpha$-motif (SAM) domains as well.

$\mathrm{Mal}$ is subject to negative regulation mediated by suppressor of cytokine signaling (SOCS)1. It was shown that SOCS1 mediates K48-linked polyubiquitination of Mal on two N-terminal lysines, thereby mediating Mal degradation via the 26 S proteasome (Mansell et al. 2006). A prerequisite for Mal degradation is tyrosine phosphorylation by Btk, as this may allow SOCS1 to associate with Mal through its SH2 domain. As already mentioned, phosphorylation of Mal by Btk potentiate signaling; thus phosphorylation by Btk allows a transient activation of downstream signaling pathways before Mal is targeted to degradation (Watters et al. 2007).

Triad3A is a novel RING-type E3 ubiquitin ligase which promotes the degradation of TLR3, TLR4, TLR5 and TLR9, but not TLR2 (Chuang and Ulevitch 2004).

The two deubiquitinating enzymes, A20 and CYLD, are induced by NF- $\kappa B$ and form an important negative-feedback loop in pro-inflammatory signaling. They function by removing K63-linked polyubiquitin chains from RIP1, TRAF and NEMO proteins (Evans 2005). A20, induced at a transcriptional level by NF- $\mathrm{\kappa B}$, terminates TLR signaling by removing ubiquitin moieties from TRAF6 (Miggin and O'Neill 2006). It also inhibits TNF and IL-1 signaling (Opipari et al. 1992; Jaattela et al. 1996). The N-terminal portion of A20 binds TRAF molecules, and the C-terminal region, containing seven $\mathrm{Zn}$ fingers, interacts with NEMO and IKKa
(Evans 2005). CYLD, identified as a tumor suppressor gene that is mutated in familiar cylindromatosis (a benign skin tumor) (Bignell et al. 2000), removes K63-linked polyubiquitin chains from TRAF2 and NEMO, and inhibits their activities (Brummelkamp et al. 2003; Kovalenko et al. 2003; Trompouki et al. 2003).

The TIR domain containing protein of vaccinia virus, A46R, sequesters TRIF via homophilic TIR domain interactions and inhibits TRIF-induced IRF-3 activation; and also targets MyD88 and TRAM (Watters et al. 2007).

A serine protease of hepatitis $C$ virus is known to cause proteolysis of TRIF (Watters et al. 2007).

TGF- $\beta$ partly exerts its anti-inflammatory effects by causing direct ubiquitination of MyD88, thereby augmenting its degradation by the proteasome (Naiki et al. 2005; Watters et al. 2007).

Glucocorticoids also inhibit actions of some TLRs, as discussed below.

\section{Specificity at the promoter level}

It was found that TLR3 and TLR4 differently regulate the IFN response. When TLR3 is activated, IRF-3 homodimers are tethered on the regulatory regions of target genes, which contain IFN-sensitive response elements (ISRE), such as IFN- $\beta$. However, when TLR4 is activated, a complex of IRF- 3 and the NF- $\kappa B$ subunit $\mathrm{p} 65$ is formed and so NF- $\kappa B$ plays a key role in the function of IRF-3 during TLR4 signaling (Wietek et al. 2003). Glucocorticoids were found to repress the induction of ISRE-containing genes, but only when activated by TLR4 as opposed to TLR3, because they specifically target and disrupt the p65/IRF complex (Doyle and O'Neill 2006).

Another example of promoter-specificity is the finding that two IFN-related genes, MCP-1 and IP-10, are differently regulated by NF- $\kappa B$. Only one nucleotide in the promoter-sequence determined the specific regulation profile (as a consequence of specificity of dimer and coactivator recruitments) (Leung et al. 2004). It was demonstrated that while the transcription of MCP-1 and IP- 10 could be induced by LPS in both wild type and p50/p52-deficient cells, only MCP-1 responded to TNF-stimulation in p50/p52-deficient cells, where the only detectable NF- $\kappa B$ dimer on the promoter was the $\mathrm{p} 65$ homodimer (Leung et al. 2004). The unresponsiveness of the IP- 10 gene to $\mathrm{p} 65$ homodimers in the TNF-treated cells is a consequence of the lack of a cofactor (IRF-3 functions as a cofactor here) that LPS can induce. Chromatin immunoprecipitation assays demonstrated that IRF- 3 was tethered to the IP- 10 promoter, but not the MCP-1 promoter, in an LPS-dependent manner (Doyle and O'Neill 2006). Under TNF stimulation, however, IRF-3 is not activated. 
Similar promoter-selective effects of p38 and JNK were observed using glucocorticoid-responsive regulatory sequences (Szatmary and Kebis 2012) indicating that the interplay between glucocorticoids and pro-inflammatory stimuli is mutually selective.

\section{Concluding remark}

Figure 1 depicts a simplified diagram of signal transduction pathways elicited by activated TLRs. Defective TLR-mediated signaling pathways are involved in the pathogenesis of many autoimmune (e.g., TLR2/4 have been shown to be involved in rheumatoid arthritis, and TLR7/8/9 in the pathogenesis of systemic lupus erythematosus, respectively) and other disorders, therefore their elucidation is a critical prerequisite for the development of new, effective therapies of these diseases.

\section{References}

Akira S. (2003): Toll-like receptor signaling. J. Biol. Chem. 278, 38105-38108 http://dx.doi.org/10.1074/jbc.R300028200

Aliprantis A. O., Yang R. B., Mark M. R., Suggett S., Devaux B., Radolf J. D., Klimpel G. R., Godowski P., Zychlinsky A. (1999): Cell activation and apoptosis by bacterial lipoproteins through toll-like receptor-2. Science $\mathbf{2 8 5}, \mathbf{7 3 6 - 7 3 9}$ http://dx.doi.org/10.1126/science.285.5428.736

Andrejeva J., Childs K. S., Young D. F., Carlos T. S., Stock N., Goodbourn S., Randall R. E. (2004): The V proteins of paramyxoviruses bind the IFN-inducible RNA helicase, mda-5, and inhibit its activation of the IFN-beta promoter. Proc. Natl. Acad. Sci. U. S. A. 101, 17264-17269 http://dx.doi.org/10.1073/pnas.0407639101

Arancibia S. A., Beltran C. J., Aguirre I. M., Silva P., Peralta A. L., Malinarich F., Hermoso M. A. (2007): Toll-like receptors are key participants in innate immune responses. Biol. Res. 40, 97-112 http://dx.doi.org/10.4067/S0716-97602007000200001

Bignell G. R., Warren W., Seal S., Takahashi M., Rapley E., Barfoot R., Green H., Brown C., Biggs P. J., Lakhani S. R., Jones C., Hansen J., Blair E., Hofmann B., Siebert R., Turner G., Evans D. G., Schrander-Stumpel C., Beemer F. A., van Den Ouweland A., Halley D., Delpech B., Cleveland M. G., Leigh I., Leisti J., Rasmussen S. (2000): Identification of the familial cylindromatosis tumour-suppressor gene. Nat. Genet. 25, $160-165$ http://dx.doi.org/10.1038/76006

Brummelkamp T. R., Nijman S. M., Dirac A. M., Bernards R. (2003): Loss of the cylindromatosis tumour suppressor inhibits apoptosis by activating NF-kappaB. Nature 424, 797-801 http://dx.doi.org/10.1038/nature01811

Carty M., Goodbody R., Schroder M., Stack J., Moynagh P. N., Bowie A. G. (2006): The human adaptor SARM negatively regulates adaptor protein TRIF-dependent Toll-like receptor signaling. Nat. Immunol. 7, 1074-1081

http://dx.doi.org/10.1038/ni1382

Chuang T. H., Ulevitch R. J. (2004): Triad3A, an E3 ubiquitinprotein ligase regulating Toll-like receptors. Nat. Immunol. 5, 495-502 http://dx.doi.org/10.1038/ni1066

Ciechanover A. (2006): Intracellular protein degradation: from a vague idea thru the lysosome and the ubiquitin-proteasome system and onto human diseases and drug targeting. Exp. Biol. Med. (Maywood) 231, 1197-1211

Cusson-Hermance N., Khurana S., Lee T. H., Fitzgerald K. A., Kelliher M. A. (2005): Rip1 mediates the Trif-dependent toll-like receptor 3- and 4-induced NF-\{kappa $\}$ B activation but does not contribute to interferon regulatory factor 3 activation. J. Biol. Chem. 280, 36560-36566 http://dx.doi.org/10.1074/jbc.M506831200

Deng L., Wang C., Spencer E., Yang L., Braun A., You J., Slaughter C., Pickart C., Chen Z. J. (2000): Activation of the IkappaB kinase complex by TRAF6 requires a dimeric ubiquitin-conjugating enzyme complex and a unique polyubiquitin chain. Cell 103, 351-361 http://dx.doi.org/10.1016/S0092-8674(00)00126-4

Doyle S., Vaidya S., O'Connell R., Dadgostar H., Dempsey P., Wu T., Rao G., Sun R., Haberland M., Modlin R., Cheng G. (2002): IRF3 mediates a TLR3/TLR4-specific antiviral gene program. Immunity 17, 251-263 http://dx.doi.org/10.1016/S1074-7613(02)00390-4

Doyle S. L., O'Neill L. A. (2006): Toll-like receptors: from the discovery of NFkappaB to new insights into transcriptional regulations in innate immunity. Biochem. Pharmacol. 72, 1102-1113 http://dx.doi.org/10.1016/j.bcp.2006.07.010

Dunne A., O'Neill L. A. (2005): Adaptor usage and Toll-like receptor signaling specificity. FEBS Lett. 579, 3330-3335 http://dx.doi.org/10.1016/j.febslet.2005.04.024

Evans P. C. (2005): Regulation of pro-inflammatory signalling networks by ubiquitin: identification of novel targets for antiinflammatory drugs. Expert Rev. Mol. Med. 7, 1-19 http://dx.doi.org/10.1017/S1462399405009415

Fitzgerald K. A., Palsson-McDermott E. M., Bowie A. G., Jefferies C. A., Mansell A. S., Brady G., Brint E., Dunne A., Gray P., Harte M. T., McMurray D., Smith D. E., Sims J. E., Bird T. A., O'Neill L. A. (2001): Mal (MyD88-adapter-like) is required for Toll-like receptor-4 signal transduction. Nature 413, 78-83 http://dx.doi.org/10.1038/35092578

Fitzgerald K. A., McWhirter S. M., Faia K. L., Rowe D. C., Latz E., Golenbock D. T., Coyle A. J., Liao S. M., Maniatis T. (2003): IKKepsilon and TBK1 are essential components of the IRF3 signaling pathway. Nat. Immunol. 4, 491-496 http://dx.doi.org/10.1038/ni921

Fukushima T., Matsuzawa S., Kress C. L., Bruey J. M., Krajewska M., Lefebvre S., Zapata J. M., Ronai Z., Reed J. C. (2007): Ubiquitin-conjugating enzyme Ubc13 is a critical component of TNF receptor-associated factor (TRAF)-mediated inflammatory responses. Proc. Natl. Acad. Sci. U. S. A. 104, 6371-6376 http://dx.doi.org/10.1073/pnas.0700548104 
Gewirtz A. T., Navas T. A., Lyons S., Godowski P. J., Madara J. L. (2001): Cutting edge: bacterial flagellin activates basolaterally expressed TLR5 to induce epithelial proinflammatory gene expression. J. Immunol. 167, 1882-1885

Gohda J., Matsumura T., Inoue J. (2004): Cutting edge: TNFR-associated factor (TRAF) 6 is essential for MyD88-dependent pathway but not toll/IL-1 receptor domain-containing adaptor-inducing IFN-beta (TRIF)-dependent pathway in TLR signaling. J. Immunol. 173, 2913-2917

Hacker H., Redecke V., Blagoev B., Kratchmarova I., Hsu L. C., Wang G. G., Kamps M. P., Raz E., Wagner H., Hacker G., Mann M., Karin M. (2006): Specificity in Toll-like receptor signalling through distinct effector functions of TRAF3 and TRAF6. Nature 439, 204-207 http://dx.doi.org/10.1038/nature04369

Hansson G. K., Edfeldt K. (2005): Toll to be paid at the gateway to the vessel wall. Arterioscler. Thromb. Vasc. Biol. 25, 1085-1087 http://dx.doi.org/10.1161/01.ATV.0000168894.43759.47

Hayashi F., Smith K. D., Ozinsky A., Hawn T. R., Yi E. C., Goodlett D. R., Eng J. K., Akira S., Underhill D. M., Aderem A. (2001): The innate immune response to bacterial flagellin is mediated by Toll-like receptor 5 . Nature 410, 1099-1103 http://dx.doi.org/10.1038/35074106

Hiscott J. (2007): Convergence of the NF-kappaB and IRF pathways in the regulation of the innate antiviral response. Cytokine Growth Factor Rev. 18, 483-490 http://dx.doi.org/10.1016/j.cytogfr.2007.06.002

Hoebe K., Du X., Georgel P., Janssen E., Tabeta K., Kim S. O., Goode J., Lin P., Mann N., Mudd S., Crozat K., Sovath S., Han J., Beutler B. (2003): Identification of Lps2 as a key transducer of MyD88independent TIR signalling. Nature 424, 743-748 http://dx.doi.org/10.1038/nature01889

Horng T., Barton G. M., Medzhitov R. (2001): TIRAP: an adapter molecule in the Toll signaling pathway. Nat. Immunol. 2, 835-841 http://dx.doi.org/10.1038/ni0901-835

Hsu L. C., Park J. M., Zhang K., Luo J. L., Maeda S., Kaufman R. J., Eckmann L., Guiney D. G., Karin M. (2004): The protein kinase PKR is required for macrophage apoptosis after activation of Toll-like receptor 4 . Nature 428, 341-345 http://dx.doi.org/10.1038/nature02405

Jaattela M., Mouritzen H., Elling F., Bastholm L. (1996): A20 zinc finger protein inhibits TNF and IL-1 signaling. J. Immunol. 156, 1166-1173

Janssens S., Beyaert R. (2003): Functional diversity and regulation of different interleukin-1 receptor-associated kinase (IRAK) family members. Mol. Cell 11, 293-302 http://dx.doi.org/10.1016/S1097-2765(03)00053-4

Kawagoe T., Sato S., Jung A., Yamamoto M., Matsui K., Kato H., Uematsu S., Takeuchi O., Akira S. (2007): Essential role of IRAK-4 protein and its kinase activity in Toll-like receptormediated immune responses but not in TCR signaling. J. Exp. Med. 204, 1013-1024 http://dx.doi.org/10.1084/jem.20061523

Kawagoe T., Sato S., Matsushita K., Kato H., Matsui K., Kumagai Y., Saitoh T., Kawai T., Takeuchi O., Akira S. (2008): Sequential control of Toll-like receptor-dependent responses by IRAK1 and IRAK2. Nat. Immunol. 9, 684-691 http://dx.doi.org/10.1038/ni.1606

Kawai T., Sato S., Ishii K. J., Coban C., Hemmi H., Yamamoto M., Terai K., Matsuda M., Inoue J., Uematsu S., Takeuchi O., Akira S. (2004): Interferon-alpha induction through Toll-like receptors involves a direct interaction of IRF7 with MyD88 and TRAF6. Nat. Immunol. 5, 1061-1068 http://dx.doi.org/10.1038/ni1118

Kawai T., Akira S. (2005): Toll-like receptor downstream signaling. Arthritis Res. Ther. 7, 12-19

http://dx.doi.org/10.1186/ar1469

Kim S., Takahashi H., Lin W. W., Descargues P., Grivennikov S., Kim Y., Luo J. L., Karin M. (2009): Carcinoma-produced factors activate myeloid cells through TLR2 to stimulate metastasis. Nature 457, 102-106 http://dx.doi.org/10.1038/nature07623

Kobayashi K., Hernandez L. D., Galan J. E., Janeway C. A., Jr., Medzhitov R., Flavell R. A. (2002): IRAK-M is a negative regulator of Toll-like receptor signaling. Cell 110, 191-202 http://dx.doi.org/10.1016/S0092-8674(02)00827-9

Kollewe C., Mackensen A. C., Neumann D., Knop J., Cao P., Li S., Wesche H., Martin M. U. (2004): Sequential autophosphorylation steps in the interleukin-1 receptor-associated kinase-1 regulate its availability as an adapter in interleukin-1 signaling. J. Biol. Chem. 279, 5227-5236 http://dx.doi.org/10.1074/jbc.M309251200

Kovalenko A., Chable-Bessia C., Cantarella G., Israel A., Wallach D., Courtois G. (2003): The tumour suppressor CYLD negatively regulates NF-kappaB signalling by deubiquitination. Nature 424, 801-805 http://dx.doi.org/10.1038/nature01802

Lemaitre B., Nicolas E., Michaut L., Reichhart J. M., Hoffmann J. A. (1996): The dorsoventral regulatory gene cassette spatzle/Toll/ cactus controls the potent antifungal response in Drosophila adults. Cell 86, 973-983 http://dx.doi.org/10.1016/S0092-8674(00)80172-5

Leung T. H., Hoffmann A., Baltimore D. (2004): One nucleotide in a kappaB site can determine cofactor specificity for NF-kappaB dimers. Cell 118, 453-464 http://dx.doi.org/10.1016/j.cell.2004.08.007

Li X., Commane M., Burns C., Vithalani K., Cao Z., Stark G. R. (1999): Mutant cells that do not respond to interleukin-1 (IL1) reveal a novel role for IL-1 receptor-associated kinase. Mol. Cell. Biol. 19, 4643-4652

Lin W. W., Karin M. (2007): A cytokine-mediated link between innate immunity, inflammation, and cancer. J. Clin. Invest. 117, 1175-1183 http://dx.doi.org/10.1172/JCI31537

Luo J. L., Maeda S., Hsu L. C., Yagita H., Karin M. (2004): Inhibition of NF-kappaB in cancer cells converts inflammation- induced tumor growth mediated by TNFalpha to TRAIL-mediated tumor regression. Cancer Cell 6, 297-305 http://dx.doi.org/10.1016/j.ccr.2004.08.012

Mansell A., Smith R., Doyle S. L., Gray P., Fenner J. E., Crack P. J., Nicholson S. E., Hilton D. J., O'Neill L. A., Hertzog P. J. (2006): Suppressor of cytokine signaling 1 negatively regulates Tolllike receptor signaling by mediating Mal degradation. Nat. Immunol. 7, 148-155 http://dx.doi.org/10.1038/ni1299 
Matsuzawa A., Tseng P. H., Vallabhapurapu S., Luo J. L., Zhang W., Wang H., Vignali D. A., Gallagher E., Karin M. (2008): Essential cytoplasmic translocation of a cytokine receptor-assembled signaling complex. Science 321, 663-668 http://dx.doi.org/10.1126/science.1157340

Meylan E., Burns K., Hofmann K., Blancheteau V., Martinon F., Kelliher M., Tschopp J. (2004): RIP1 is an essential mediator of Toll-like receptor 3-induced NF-kappa B activation. Nat. Immunol. 5, 503-507 http://dx.doi.org/10.1038/ni1061

Miggin S. M., O'Neill L. A. (2006): New insights into the regulation of TLR signaling. J. Leukoc. Biol. 80, 220-226 http://dx.doi.org/10.1189/jlb.1105672

Naiki Y., Michelsen K. S., Zhang W., Chen S., Doherty T. M., Arditi M. (2005): Transforming growth factor-beta differentially inhibits MyD88-dependent, but not TRAM- and TRIF-dependent, lipopolysaccharide-induced TLR4 signaling. J. Biol. Chem. 280, 5491-5495 http://dx.doi.org/10.1074/jbc.C400503200

Negishi H., Fujita Y., Yanai H., Sakaguchi S., Ouyang X., Shinohara M., Takayanagi H., Ohba Y., Taniguchi T., Honda K. (2006): Evidence for licensing of IFN-gamma-induced IFN regulatory factor 1 transcription factor by MyD88 in Toll-like receptordependent gene induction program. Proc. Natl. Acad. Sci. U.S.A. 103, 15136-15141 http://dx.doi.org/10.1073/pnas.0607181103

Nizet V. (2006): Antimicrobial peptide resistance mechanisms of human bacterial pathogens. Curr. Issues Mol. Biol. 8, $11-26$

O'Neill L. A. (2002): Toll-like receptor signal transduction and the tailoring of innate immunity: a role for Mal? Trends Immunol. 23, 296-300 http://dx.doi.org/10.1016/S1471-4906(02)02222-6

O'Neill L. A. (2006): How Toll-like receptors signal: what we know and what we don't know. Curr. Opin. Immunol. 18, 3-9 http://dx.doi.org/10.1016/j.coi.2005.11.012

Opipari A. W., Jr., Hu H. M., Yabkowitz R., Dixit V. M. (1992): The A20 zinc finger protein protects cells from tumor necrosis factor cytotoxicity. J. Biol. Chem. 267, 12424-12427

Pietras E. M., Saha S. K., Cheng G. (2006): The interferon response to bacterial and viral infections. J. Endotoxin Res. 12, 246-250 http://dx.doi.org/10.1179/096805106X118799

Sasai M., Oshiumi H., Matsumoto M., Inoue N., Fujita F., Nakanishi M., Seya T. (2005): Cutting Edge: NF-kappaB-activating kinaseassociated protein 1 participates in TLR3/Toll-IL-1 homology domain-containing adapter molecule-1-mediated IFN regulatory factor 3 activation. J. Immunol. 174, 27-30

Szatmary Z., Kebis A. (2012): Promoter-context as a determinant of glucocorticoid receptor-responsiveness to activation of $\mathrm{p} 38$ and JNK mitogen-activated protein (MAP) kinases. Gen. Physiol. Biophys. 31, 309-322 http://dx.doi.org/10.4149/gpb_2012_036

Takaoka A., Yanai H., Kondo S., Duncan G., Negishi H., Mizutani T., Kano S., Honda K., Ohba Y., Mak T. W., Taniguchi T. (2005): Integral role of IRF-5 in the gene induction programme activated by Toll-like receptors. Nature 434, 243-249 http://dx.doi.org/10.1038/nature03308
Takayanagi H., Kim S., Matsuo K., Suzuki H., Suzuki T., Sato K., Yokochi T., Oda H., Nakamura K., Ida N., Wagner E. F., Taniguchi T. (2002): RANKL maintains bone homeostasis through c-Fosdependent induction of interferon-beta. Nature 416, 744-749 http://dx.doi.org/10.1038/416744a

Takayanagi H., Sato K., Takaoka A., Taniguchi T. (2005): Interplay between interferon and other cytokine systems in bone metabolism. Immunol. Rev. 208, 181-193 http://dx.doi.org/10.1111/j.0105-2896.2005.00337.x

Trompouki E., Hatzivassiliou E., Tsichritzis T., Farmer H., Ashworth A., Mosialos G. (2003): CYLD is a deubiquitinating enzyme that negatively regulates NF-kappaB activation by TNFR family members. Nature 424, 793-796 http://dx.doi.org/10.1038/nature01803

Tseng P. H., Matsuzawa A., Zhang W., Mino T., Vignali D. A., Karin M. (2010): Different modes of ubiquitination of the adaptor TRAF3 selectively activate the expression of type I interferons and proinflammatory cytokines. Nat. Immunol. 11, 70-75 http://dx.doi.org/10.1038/ni.1819

Uematsu S., Sato S., Yamamoto M., Hirotani T., Kato H., Takeshita F., Matsuda M., Coban C., Ishii K. J., Kawai T., Takeuchi O., Akira S. (2005): Interleukin-1 receptor-associated kinase-1 plays an essential role for Toll-like receptor (TLR)7- and TLR9-mediated interferon-\{alpha\} induction. J. Exp. Med. 201, 915-923

http://dx.doi.org/10.1084/jem.20042372

Ulevitch R. J. (1999): Toll gates for pathogen selection. Nature 401, 755-756 http://dx.doi.org/10.1038/44490

Underhill D. M., Ozinsky A., Hajjar A. M., Stevens A., Wilson C. B., Bassetti M., Aderem A. (1999): The Toll-like receptor 2 is recruited to macrophage phagosomes and discriminates between pathogens. Nature 401, 811-815 http://dx.doi.org/10.1038/44605

Wang C., Deng L., Hong M., Akkaraju G. R., Inoue J., Chen Z. J. (2001): TAK1 is a ubiquitin-dependent kinase of MKK and IKK. Nature 412, 346-351 http://dx.doi.org/10.1038/35085597

Watters T. M., Kenny E. F., O'Neill L. A. (2007): Structure, function and regulation of the Toll/IL-1 receptor adaptor proteins. Immunol. Cell Biol. 85, 411-419 http://dx.doi.org/10.1038/sj.icb.7100095

Wietek C., Miggin S. M., Jefferies C. A., O'Neill L. A. (2003): Interferon regulatory factor-3-mediated activation of the interferon-sensitive response element by Toll-like receptor (TLR) 4 but not TLR3 requires the p65 subunit of NF-kappa. J. Biol. Chem. 278, 50923-50931 http://dx.doi.org/10.1074/jbc.M308135200

Yamamoto M., Sato S., Mori K., Hoshino K., Takeuchi O., Takeda K., Akira S. (2002): Cutting edge: a novel Toll/IL-1 receptor domain-containing adapter that preferentially activates the IFN-beta promoter in the Toll-like receptor signaling. J. Immunol. 169, 6668-6672

Yamamoto M., Okamoto T., Takeda K., Sato S., Sanjo H., Uematsu S., Saitoh T., Yamamoto N., Sakurai H., Ishii K. J., Yamaoka S., Kawai T., Matsuura Y., Takeuchi O., Akira S. (2006): Key function for the Ubc13 E2 ubiquitin-conjugating enzyme in immune receptor signaling. Nat. Immunol. 7, 962-970 
http://dx.doi.org/10.1038/ni1367

Yamin T. T., Miller D. K. (1997): The interleukin-1 receptor-associated kinase is degraded by proteasomes following its phosphorylation. J. Biol. Chem. 272, 21540-21547 http://dx.doi.org/10.1074/jbc.272.34.21540

Yoneyama M., Kikuchi M., Natsukawa T., Shinobu N., Imaizumi T., Miyagishi M., Taira K., Akira S., Fujita T. (2004): The RNA helicase RIG-I has an essential function in double-stranded RNA-induced innate antiviral responses. Nat. Immunol. 5, 730-737

http://dx.doi.org/10.1038/ni1087

Received: February 13, 2012

Final version accepted: June 7, 2012 